\section{Zahnmedizin Report}

\section{Zahnärzte finden Universal-Adhäsiv} \section{„sehr gut"}

Zeitsparend und einfach anzuwenden, dabei aber sicher und effektiv: Mit diesen Eigenschaften überzeugte das UniversalAdhäsiv Futurabond U von VOCO die TestZahnärzte des Zahnmedizin Reports. Sie unterzogen das Bonding dem Praxistest und bewerteten es mit 5 von 5 Sternen. Das dualhärtende Bonding ist für direkte und indirekte Restaurationen geeignet und lässt dem Zahnarzt die freie Wahl, ob es im Self-Etch-, Selective-Etch- oder Total-Etch-Modus angewendet wird. Außer- dem ist es - ohne zusätzlichen Aktivator - kompatibel mit allen licht-, dual- und selbsthärtenden Kompositen und sorgt ohne zusätzlichen Primer für eine sichere Haftung an diversen Materialien wie Metall, Zirkon- und Aluminiumoxid sowie Silikatkeramik. Über einen Zeitraum von rund 3 Monaten testeten Universal-Adhäsiv-erfahrene Zahnärzte Futurabond U und notierten ihre Erfahrungen mit dem Haftvermittler. Diese fielen „gut“, häufig sogar „sehr gut“ aus: Positiv bewertet wurden die hygienische SingleDose, die allgemeine Handhabung und Verarbeitung des Materials, die Kompatibilität

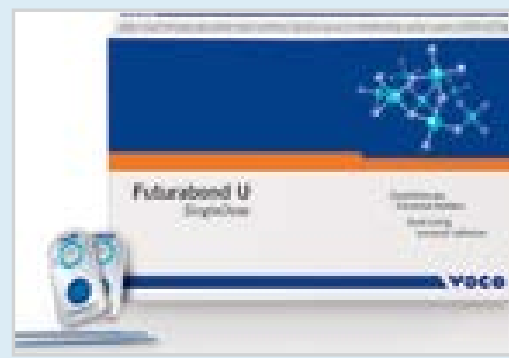

handelsüblichen Kompositen, die Vielseitigkeit der Indikationen und die Flexibilität des Ätz-Modus. Die Einzelheiten sind nachzulesen im Praxistest des Zahnmedizin Report, Ausgabe 6-2015.

Nach einer Pressemitteilung der

voCO GmbH, Cuxhaven 